\title{
Prosecuting for knowingly transmitting HIV is warranted
}

A bout 6 years ago I met a new patient who was told on her 19th birthday that she was HIV infected. She had been in a relationship with a man 8 years older. Although he knew that he was HIV positive, she did not. He had been thoroughly counselled and knew all about HIV transmission.

The patient fell in love with this man. He did not disclose his status. They initially used condoms but after a while he began to cajole her, saying that condoms were unnecessary and that he had no infections, specifically HIV. He lied to her, exploited her affection for him, reassured her and charmed her. She agreed not to use condoms and he infected her.

The patient was devastated and felt that he should be stopped from infecting others in the same fashion. She called the police and public health authorities, but neither responded. About a year later, by chance, she met another young woman who this man had tried to seduce without condoms, lying about his status. Lucky for her, the young woman refused. My patient was furious and again called the police and public health who took her complaints a lot more seriously. The man was charged, his photo splashed in the media to warn other possible victims (and to ensure that they get tested) and he pled guilty. He was sentenced to 4.5 years in jail.

The man's behaviour satisfied the criteria for prosecution set down by even the most ardent opponents of the use of criminal law in HIV-transmission cases. Edwin Cameron, an HIV-positive Justice of the Supreme Court of Appeal in South Africa wrote: "The use of criminal law to address HIV infection is inappropriate except in rare cases in which a person acts with conscious intent to transmit HIV and does so." UNAIDS states that it "... urges governments to limit criminalization to cases of intentional transmission i.e. where a person knows his or her HIV positive status, acts with the intention to transmit HIV, and does in fact transmit it." 2 The man who infected my patient and tried to infect another woman acted deliberately and maliciously and should be held accountable by the state for his conduct.

Some argue that criminal prosecution will dissuade persons from being tested for HIV and therefore promote HIV transmission by these persons who do

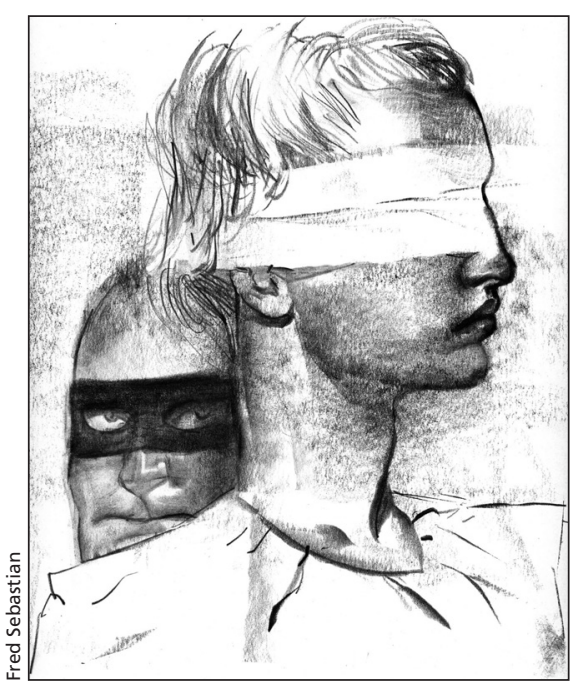

not know their status. ${ }^{3}$ Such speculation is unsupported by a single published study. No informed and reasonable person would decline HIV testing, thus placing themselves at risk of grave illness and death, just because of the publicized prosecution of some HIV-infected individuals accused of unlawfully transmitting the disease to others. It is not one's HIV infection itself that is the subject of prosecution, it is the intentional or reckless transmission of HIV to others.

Spokespersons for AIDS organizations, anxious about the stigma arising from criminal prosecutions, properly object to including HIV-specific provisions in Canada's Criminal Code. However, protecting HIV-positive persons from any criminal consequence of egregious behaviour can only add to such stigma since HIV-infected persons would then be treated differently than anybody else who deliberately hurts others. HIV infection in and of itself should not automatically exempt those who purposefully or recklessly infect others from the full application of criminal law.
The absence of standard prosecutorial criteria for triggering criminal charges in cases of HIV transmission has fed the solipsistic opposition to the appropriate application of criminal law. UNAIDS opposes the prosecution of those who do not know their HIV status. But what about persons at high risk, who have been told that they exhibit the classic physical signs of HIV infection and have been counselled on transmission and prevention? Such persons should not be excused from criminal liability for nondisclosure and deliberate infection of others simply because they have declined HIV testing. Still, it would be outrageous to apply criminal law in the case of an HIV-infected woman about to be raped, for her failure to disclose. Similarly, criminal prosecution would be inappropriate in the more common situation of an HIV-infected woman who risks harm or being killed if she discloses to her male partner. It is time to establish the reasonable threshold of HIV transmission behaviour that should justifiably lead to criminal prosecution.

An HIV-infected colleague familiar with my views, recently chastised me for being dismissive of the "complex realities within which" people with HIV lead their lives. That reality also includes the patient who received an HIV diagnosis on her 19th birthday.

\section{Philip B. Berger MD \\ Chief \\ Department of Family and \\ Community Medicine \\ St. Michael's Hospital \\ Toronto, Ont.}

\section{REFERENCES}

1. Burris $\mathrm{S}$, Cameron E. The case against criminalization of HIV transmission. JAMA 2008;300:578-80.

2. Criminalization of HIV transmission [policy brief] Geneva (Switzerland): UNAIDS; 2008.

3. Wainberg MA. Criminalizing HIV transmission may be a mistake. CMAJ 2009;180:688

Have you got an opinion about this article? Post your views at www.cmaj.ca. 